\title{
Smart Door Lock Berbasis QR Code
}

\author{
Abdul Basit ${ }^{1}$, Alif Sya'Bani Putra ${ }^{2}$, Garnis Ayu Revira ${ }^{3}$, Ririn Nur Widia ${ }^{4}$ \\ Email: elangputih286@gmail.com, alifsyabanip@gmail.com, \\ garnis@gmail.com, ririnwidia0097@gmail.com \\ Politeknik Harapan Bersama
}

\begin{abstract}
Abstrak
Keamanan merupakan salah satu hal yang sangat penting bagi sebuah perusahaan atau perkantoran dalam proses penyimpanan dan mengamankan sebuah barang atau aset sebuah kantor maupun document rahasia. Ruangan penyimpanan document harus baik dalam keamanannya agar tidak terjadi suatu hal yang merugikan Lembaga terkait, salah satu bagian yang perlu untuk ditingkatkan keamanannya adalah pintu, karena pintu menjadi akses pertama sebuah ruangan. Smart door lock merupakan pintu otomatis berbasis $Q R$ code cukup kuat dalam segi keamanan dan mudah pengoperasiannya karena menggunakan aplikasi yang berbasis android. Qr code difungsikan sebagai penyimpanan data pengguna yang sudah di daftarkan melalui website, sebagai sistem agar solenoid Door Lock bisa dibuka secara otomatis. beberapa komponen yang digunakan dalam mengembangkan penilitian ini meliputi: Raspberry pi 3, pi camera, selenoid, relay 2 channel untuk daya raspberry pi 3, smartphone android untuk menunjukkan qrcode agar pengguna bisa mengakses pintu kantor tersebut, website digunakan untuk menampilkan monitoring pengguna dalam mengakses pintu.
\end{abstract}

Kata kunci : QR-Code, Aplikasi, Rapsbery pi 3, pi camera, Smart door lock

\section{Pendahuluan}

Keamanan merupakan salah satu hal yang sangat penting bagi sebuah perusahaan atau perkantoran dalam proses penyimpanan dan mengamankan sebuah barang atau aset sebuah kantor maupun document rahasia. Sistem keamanan yang handal menjadi sebuah keharusan, dengan membangun sistem keamanan berbasis QR Code sebagai media autentifikasinya sebagai tahap seleksi bagi pengguna untuk mengakses ruangan tersebut karena hanya orang yangmemiliki akses yang dapat masuk ruangan tersebut.

Pintu menjadi bagian paling utama dalam sebuah keamanan sistem karena menjadi jalan utama yang bisa di akses disebuah dalam hal keamanan, keamanan sistem yang ketat dan kuat menjadi hal yang sangat penting untuk mengamankan aset yang cukup berharga ataupun rahasia, dengan penggunaan QR Code sebagai media autentifikasi sistem keamanan pintu bisa terjaga dengan baik karena dengan sistem ini orang yang terdaftardi sistem saja yang yang bisa mengakses pintu tersebut untuk masuk kedalam ruangan.

QR Code bisa digunakan untuk hak akses pengunanadalam membuka sistem keamanan pintu dengan memanfaatkan aplikasi android sebagai media scane dan webserver sebagai database untuk monitoring pengguna yang masuk melewatu pintu[1].

Tujuan dari penelitian ini adalah untuk menghasilkan sebuah sistem keamanan pintu berbasis QR code sebagai pengganti kunci manual untuk memperoleh hak akses pada pintu kantor dan dapat menghindari resiko terjadinya kehilangan data, sehingga masyarakat tidak dapat keluar masuk ruang kantor pegawai tersebut dengan bebas atau tidak teratur

\section{Metode Penelitian}

Prosedur penelitian digunakan segai pengumpulan beberapa data guna menjawab pernyataan dari proses penelitian yang diajukan dalam penelitian ini, dengan membahas menganai objek penelitian, latar belakang dan desain penelitian untuk tahap persiapan, pelaksanaan dan pelaporan penelitian, proses pengembangan, serta proses pengumpulan data dan alasan logisnya, dan dilanjutkan dengan analis data. Prosedur penelitian yang akan dilakukan dengan penjelasan dari masing-masing bagan seperti pada gambar 1 . 


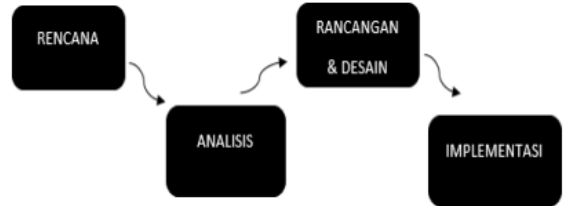

Gambar 1. Alur Penelitian

\section{Rencana / Planning}

Dilakukan sebuah perencanaan pada penelitian dengan membuat perancangan sistem Smart Door Loock/ pintu otomatis berbasis QR Code (Quick Response Code) dengan pengunaan aplikasi dan website untuk penyimpanan data yang diperlukan di penelitian ini.

\section{Analisis}

Tahap ini dimulai dengan proses memeriksa seluruh data yang sudah tersedia dari sumber yang sudah ditentukan, Dengan melakukan pengamatan dokumen yang sudah tercatat dilapangan, seperti data rahasisa, data penting maupun data pribadi. Melalui data statistic, video, gambar ataupun dari data publikasi yang tersedia sebagai pendukung untuk membuat sistem smart Door Lock pada perkantoran berbasis QR code dengan media aplikasi android.

\section{Rancangan dan Desain}

Merancang pintu otomatis / Smart Door Lock berbasis QR Code dengan media atau interface aplikasi android dan website sebagai database seluruh data yang dipelukan dalam penelitian ini.

\section{Perancangan Sistem}

Perancangan yang digunakan adah UML atau Unified Modeling Language, flowchart diagram dan diagram blok dengan aplikasi sparx interprace architect. Website dibuat dengan menggunakan PHP sebagai Bahasa pemrograman dan CI (code igniter) sebagai framewaork dan databsenya menggunakan MySQL. Kemudian aplikasi menggunakan javascript dan webview dengan apliakasi visual code dan android studio. Perncancangan sistem ini di identifikasi dengan actor dimana setiap actor memiliki beberapa aktifitas dan relesi sendiri yang bisa dilakukasn seperti berikut :
1. $U M L$

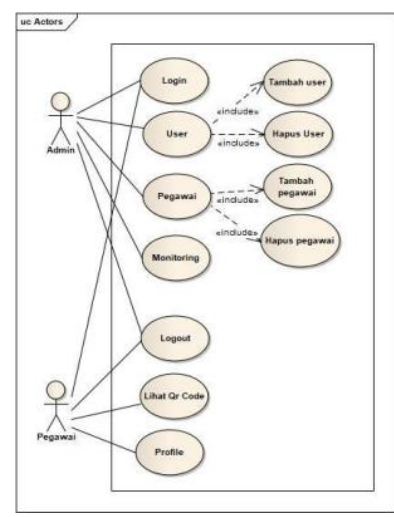

Gambar 2. Usecase Diagram

2. Diagram Blok

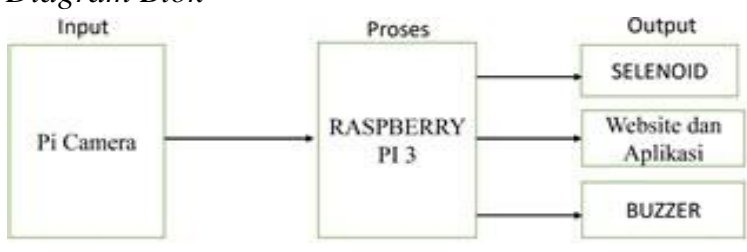

Gambar 3. Diagram Blok

3. Desain Input Output Hardware

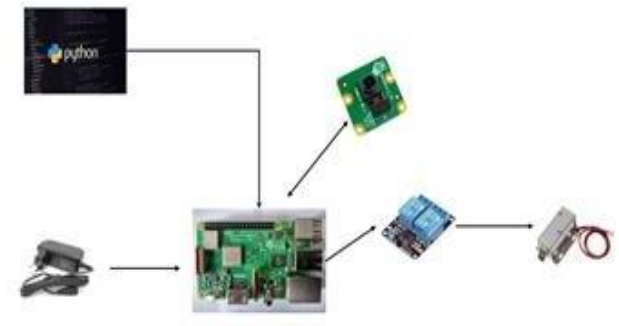

Gambar 4. Dessain Input Output

4. Flowchart

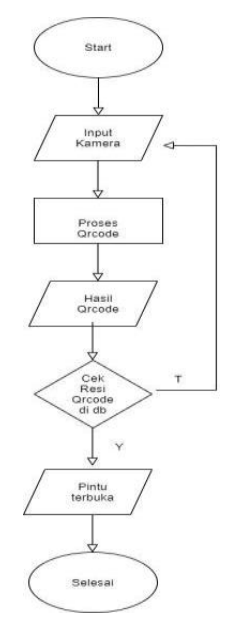

Gambar 5. Flochart Diagram 


\section{Hasil dan Pembahasan}

Setelah dilakukan metodologi penelitian maka didapatkan sebuah analisi sistem, dan analisi perangkat lunak serta hardware yang digunakan untuk membuat sistem pintu otomatis atau smart door look pada perkantoran berbasis QR Code dengan implementasi sebauh prototype.

Aplikasi android diguakan untuk interface dan controlling perangkat elektronik pada pintu ruangan dimana sistem ini bertujuan untuk memperoleh hak akses sebuah ruangan terhadap pengguna. projek ini dibuat untuk efisiensi dalam pengontrolan pengguna yang punya hak akses pintu dengan tujuan agar sistem keamanan bisa lebih ketat dan kuat lagi dan dimudahkan dengan adanya monitoring data pengguna.

\section{Implementasi hardware}

Implemantasi prangkat keras dilakukan denga memulai proses instaslasi alat dan perakitan. Bebrapa perangkat keras yang digunakan melitpui rapsbery pi 3 , pi camera, adaptor, solenoid, kabel jumper dan interface prototype smart door lock berbasis QR Code.

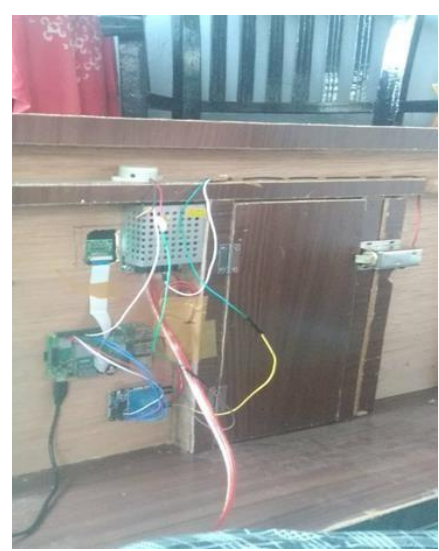

Gambar 6. interface Alat

\section{Implementasi pada Perangkat Lunak}

Diperlukan Sebuah Software untuk pengelolaan kode program yang di pergunakan pada website

\section{Interface Website}

Untuk Implementasi perangkat lunak diperlukan sebuah software untuk mengembangkan program yang digunakan pada website agar interface bisa lebih mudah digunakan oleh pengguna.
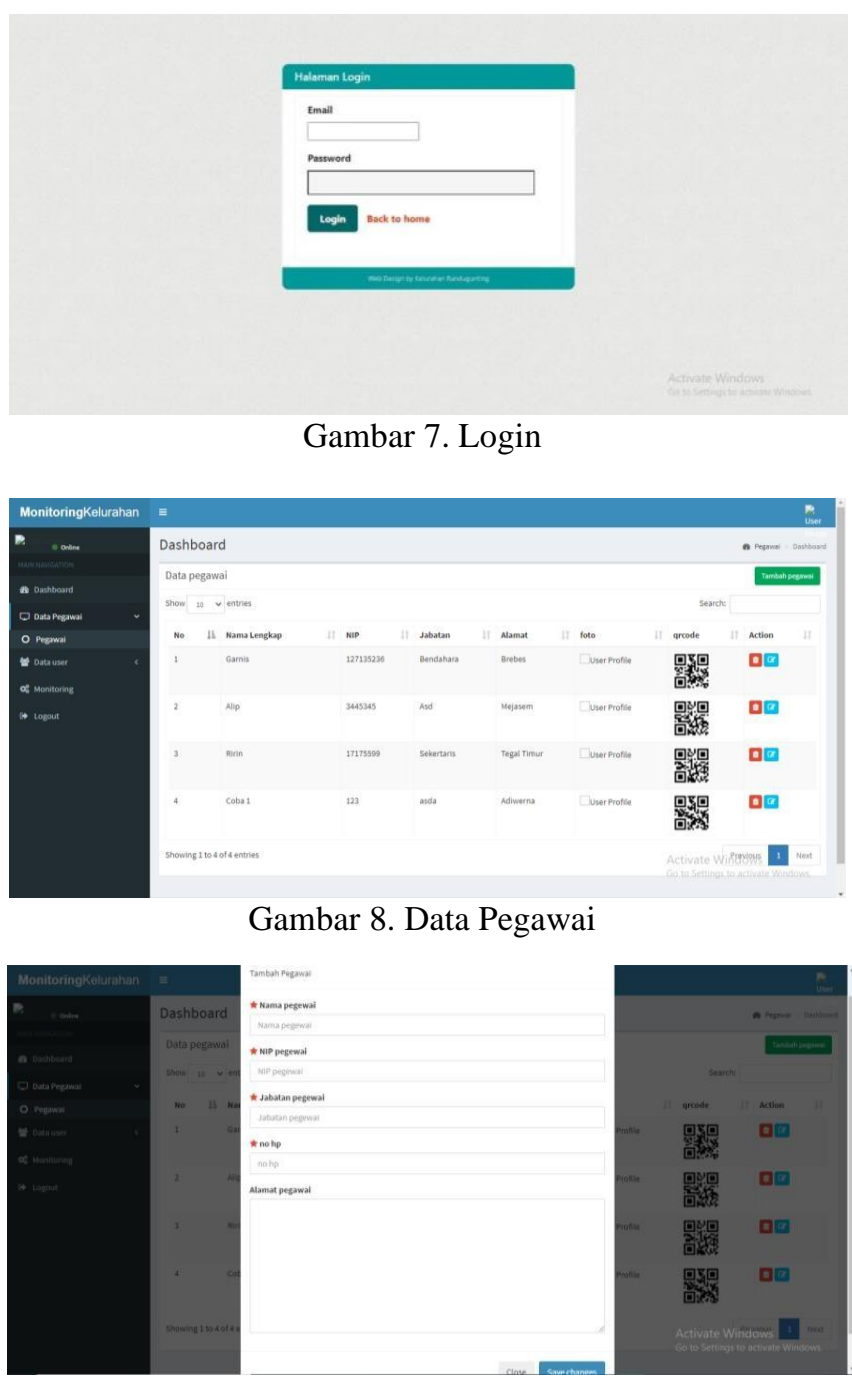

Gambar 9. Tambah Data Pegawai

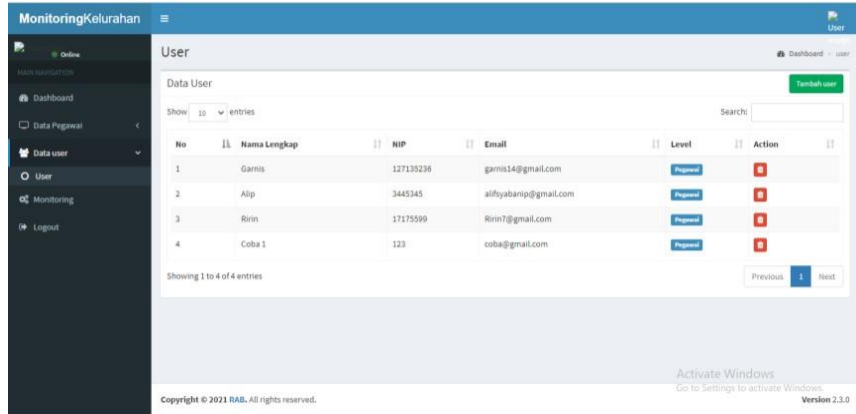

Gambar 10. Data User

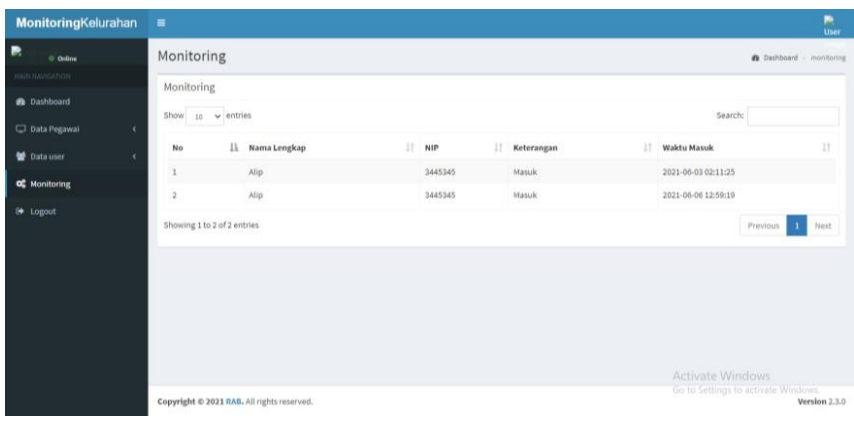

Gambar 11. Monitoring data 


\section{Interface Mobile Aplikasi}

Interface android digunakan untuk mempermudah pengguna Ketika akan membuka pintu otomatis dengan menggunakan Qr Code.

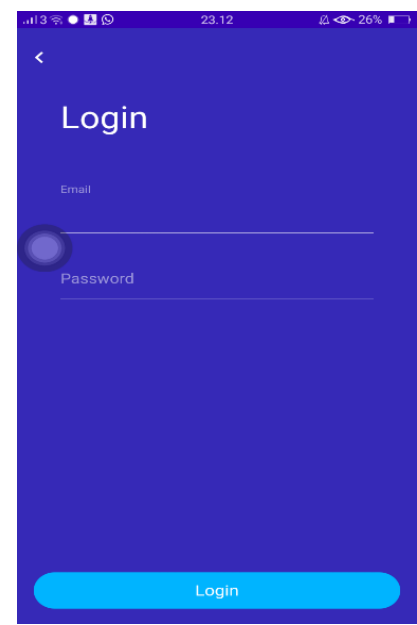

Gambar 12. Login Aplikasi

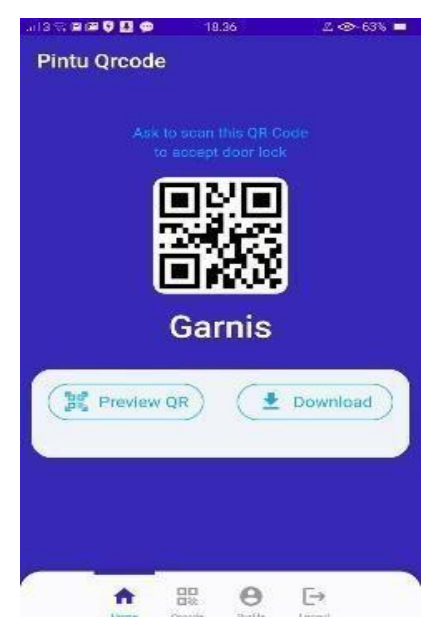

Gambar 13. interface Android

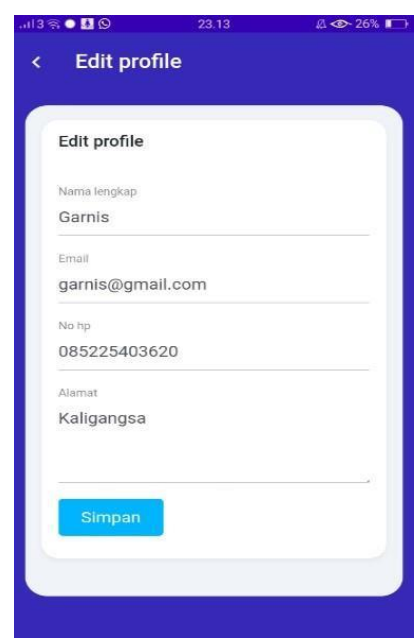

Gambar 14. Profile pengguna

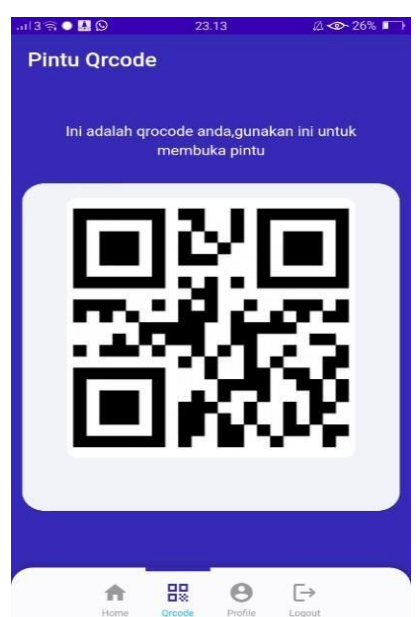

Gambar 15. Preview QR Code dari Aplikasi

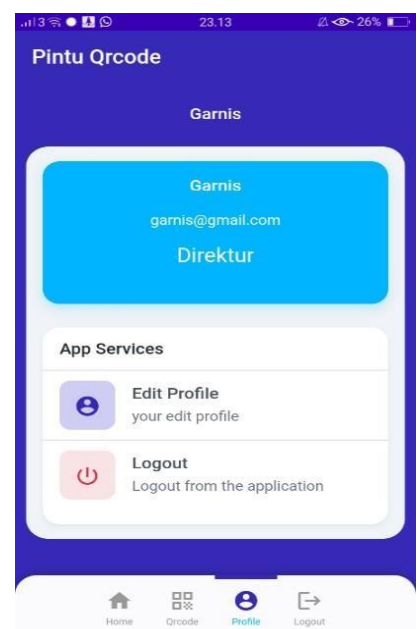

Gambar 16. Profil User dan Logout dari Aplikasi

\section{Pengujian Sistem}

Dilakukan pengujian sistem untuk menentukan apakah sistem sudah berjalan degan sebagaimana mestinya atau masih terdapat sebuah bug atau error di sistem agar bisa dilakukan proses Analisa atau perubahan di sistem. 


\section{Tabel pengujian penggunaan alat}

\begin{tabular}{ccccc}
\hline $\begin{array}{c}\mathbf{N} \\
\mathbf{0}\end{array}$ & Tanggal & Pembacaan & Hasil & Keterangan \\
\hline 1. & 01 Juni & Terbaca & Berhasil & $\begin{array}{c}\text { akses } \\
\text { Terbuka }\end{array}$ \\
\hline 2. & 01 Juni2021 & Tidak Terbaca & Tidak & akses \\
& & terdaftar & tertutup \\
\hline 3. & 02 Juni 2021 & Terbaca & Berhasil & $\begin{array}{c}\text { akses } \\
\text { terbuka }\end{array}$ \\
\hline 4. & 02 Juni 2021 & Tidak Terbaca & Tidak & $\begin{array}{c}\text { akses } \\
\text { tertutup }\end{array}$ \\
\hline
\end{tabular}

4. Kesimpulan

Kesimpulan di ambil dari pengujian yang telah dilakukan dan di ambil beberapa kesimpulan sebagai berikut:

1. Pi Camera mendeteksi QR Code yang telah terdaftar pada website.

2. website smart door pada kantor menggunakan QR code memberikan monitoring data pegawai yang menggunakan rancangan website code igniter dan bootstrap, mampu memberikan data secara real-time.

3. Digunakan smartphone berbasis android untuk mengakses dengan scan QR Code yang sudah terdaftar di website ke pi camera, maka pintu otomatis akan terbuka, dan setiap pengguna yang mengakses pintu tersebut dengan QR Code maka data akan langsung bisa dimonitoring menggunakan website.

\section{Daftar Pustaka}

[1] P. Studi, T. Elektro, F. Teknologi, I. Dan, and U. T. Yogyakarta, "Menggunakkan Qr-Code," 2018.

[2] E.Riyanto,"SISTEMKEAMANAN RUMAH BERBASIS ANDROID DENGAN RASBERRY Pi," J. Inform. Upgris, vol. 5, no. 1, pp. 5559, 2019, doi: 10.26877/jiu.v5i1.3214

[3] R. B. Santoso et al., "Rancang Bangun Smarthome Berbasis QR Code Dengan Mikrokontroller Module ESP32," vol. 2, no. 1, pp. 4760, 2021.

[4] T. Lonika and S. Hariyanto, "Simulasi Smart Door Lock Berbasis QR Code Menggunakan Arduino Uno pada Penyewaan Apartemen Online," vol. 1, pp. 9-15, 2019.

[5] A. R. Gifari Alim Prakasa, "Prototype Sistem Kunci Pintu Berbasis," 2017 